\title{
Transatlantica
}

Revue d'études américaines. American Studies Journal

\section{Some Reflections on Children's Media Cultures: An Interview with David Buckingham}

\section{Thibaut Clément and David Buckingham}

\section{(2) OpenEdition}

Journals

Electronic version

URL: https://journals.openedition.org/transatlantica/15152

DOI: 10.4000/transatlantica.15152

ISSN: 1765-2766

\section{Publisher}

Association française d'Etudes Américaines (AFEA)

Electronic reference

Thibaut Clément and David Buckingham, "Some Reflections on Children's Media Cultures: An Interview with David Buckingham", Transatlantica [Online], 2 | 2019, Online since 01 October 2020 connection on 01 February 2023. URL: http://journals.openedition.org/transatlantica/15152 ; DOI: https://doi.org/10.4000/transatlantica.15152

This text was automatically generated on 1 February 2023.

\section{(†)

Creative Commons - Attribution-NonCommercial-NoDerivatives 4.0 International - CC BY-NC-ND 4.0 https://creativecommons.org/licenses/by-nc-nd/4.0/ 


\title{
Some Reflections on Children's Media Cultures: An Interview with David Buckingham
}

\author{
Thibaut Clément and David Buckingham
}

1 Thibaut Clément: Speaking from a British perspective, what would you call the most striking features specific to the US child media market? And of those traits and processes, which do you think have since come to be adopted and replicated elsewhere?

David Buckingham: Of course, it's dangerous to generalise: the media environments of the UK and the US are increasingly diverse, depending on which media and which sections of the children's market we're talking about. I have spent a lot of my career focusing on television, and there I think we can identify some very clear differences. Broadly speaking, children's television in Britain (and elsewhere in Europe) has been part of the overall "public service" tradition; while in the US, it has been much more driven by the commercial market. The contrasts here raise some very fundamental questions about how and what the market can provide for children, and what it fails to provide.

3 Public service media tend to construct children as a special category, which is in need of particular kinds of protection and provision. This is evident, not just in content, but also in things like scheduling and promotion. Yet the danger here is that children are sometimes seen in rather sanctimonious, patronising terms: children are vulnerable and precious, and they need to be carefully nurtured. By contrast, the market-driven approach tends to construct children as active consumers, with autonomous needs and desires that do not necessarily meet with adult approval. These two systems embody quite different constructions of childhood itself-or, we might say, they attribute different kinds of value to children.

However, these are more like ideal types than descriptions of reality. In practice, in both cases, we have had mixed systems. For most of its history, television in the UK has been a complex mix of public service and commercial providers; although (at least with terrestrial channels) the latter are also subject to government regulation. The US is 
more fully commercial, but you still have interesting exceptions-as for example in the case of Sesame Street, which is itself a very particular combination of public and commercial imperatives.

The situation is also complicated by the fact that children's media are not only targeted at children, but also in many instances at parents. They have to speak to children's wants and desires, but they also have to provide things that parents will see as somehow "good for children." In the US, for example, there is a great deal of money to be made from "edutainment"-TV shows (and other media) that target parents' educational aspirations for their children, while also entertaining kids.

There have also been some historical shifts in the balance of forces here; and especially in recent years, the massive proliferation of television and other media, and the intensified competitiveness in the marketplace, has had mixed implications for children. Public service providers like the BBC now have to compete with commercial companies in a global market. Specialist children's channels have skilfully addressed specific categories of children which have been somewhat neglected in the past; and we have seen really significant creative innovation in areas like preschool programming and animation.

7 However, these developments also raise the difficult question of what the market cannot-or at least does not-provide; and the extent to which these failures can be addressed though public funding. Even confining ourselves to television, there is vastly more material available to children now than was the case even twenty years ago. Yet in the UK, we are finding that specific groups such as older children (early teenagers), and also specific genres such as factual programmes or live action drama, tend to be marginalised because they are seen as less profitable.

8 I've been talking about television here: the situation is different, and perhaps even more diverse and complicated, in other media. I suspect that the sheer size of the US market means that there is not just a greater quantity of material for children, but also greater diversity-so, for example, there is a longer history of multicultural publishing for children in the US than there is in the UK. However, the increasingly commercial orientation of children's media also means that certain groups, and certain needs, are likely to be neglected if they don't immediately offer the promise of financial profit.

TC: The theme of children's agency features prominently in your work: you insist that children are active in making sense of media, though you warn that too often critics are quick to equate children's empowerment with mere consumer sovereignty. User-generated content and social media have upended traditional hierarchies between adult producers and child audiences (though, of course, the majority of the profits derived from child-created content still goes to the adults operating the platforms). Does the fact that children are now increasingly in the position of content creators improve their media literacy? And does children's participation in content creation effectively expand their agency within the realm of the media?

DB: To begin, I think it's very important that we do not confuse agency with activity. Audiences may be very "active," in all sorts of ways, but that does not necessarily mean they have power-and that is what is implied by the idea of "agency." 
11 There is a history of these debates. Back in the 1980s, when many Cultural Studies scholars turned to empirical audience research, we were keen to insist that audiences were "active"-by contrast with other researchers (like those in the "media effects" tradition) who implicitly saw them as passive victims. "Activity" at this point referred to forms of cognitive activity (audiences were actively "making sense" of media), as well as social activity (audiences were using media in constructing social identities and relationships).

By the 1990s, some researchers turned their attention to media fans, who were more obviously "active" in a creative sense: they were making their own media (fan fiction, art and video "mashups"), albeit often using resources they had appropriated from the original texts. Again, this was partly in reaction against an earlier view, which saw fans as somehow enslaved or pathological.

13 There is certainly a risk of merely celebrating these different forms of "activity," and particularly of overestimating the power that they afford to audiences. I think we should be particularly careful of assuming that fans are somehow typical of media audiences more broadly. We are all actively making sense of media, and actively using media, but we are not able to do so in any way we choose. The power of audiences needs to be set against the power of media representations, and of media industries. And fans, however "active" they may be, are also quintessentially consumers.

14 The advent of digital and social media brought this debate into sharper focus. Once again, there were some who positively celebrated the creative possibilities of these new media; and this wasn't just about cognitive activity, it was also about ordinary people becoming media producers and communicators in their own right. For some, this appeared to mean the demise of powerful media corporations, and the emergence of a kind of democratic creative utopia.

15 Twenty years on from "Web 2.0," it's much harder to maintain that optimistic view. It's not just that people have become increasingly aware of the potential risks-and when it comes to children, the debate is dominated by concerns about pornography and paedophiles, cyberbullying and hate speech, threats to privacy, and so on. It's also that we have become increasingly aware of the economic model of these media-the fact that a service which appears to be free, and which we appear to control, is actually based on the gathering and selling of our personal data.

16 So, on one level, I would agree that these newer media have created new opportunities for children and young people (and indeed for adults) to engage in creative mediamaking. Yet while we might be making media, we are doing so under conditions that are not of our own choosing. The system whereby these media reach audiencesthrough technologies of search and recommendation, for example-is governed by algorithms that we do not control, or even really know about. Far from resulting in a flowering of autonomous creativity or a revival in democratic politics-as some of the utopian pioneers predicted-we are heading towards a situation where communication and culture are much more intensively and pervasively commercialised.

17 The world of YouTube "influencers" would be an interesting example. Here we have (some) children and (rather more) older young people creating their own media content, finding their voices, expressing themselves, being creative. Yet they are doing so in a context that is commercially defined and constructed, and where "influence" is mostly defined in quite particular commercial ways. They are selling things, and 
simultaneously selling themselves: the adult logic of "celebrity" now applies to children. And, as you say, much of the profit is ending up in the hands of the massive data companies. If this is "empowerment" or agency, then it is a very limited and superficial form of it.

As for media literacy, that's a whole other debate! "Literacy" obviously implies both reading and writing; but in my view it has to have a critical dimension. Among educators, there is sometimes a rather superficial celebration of the wonders of children's digital creativity. I don't believe that the experience of making media in itself necessarily produces critical understanding, or that these new creative possibilities make media analysis unnecessary, as some people suggest. On the contrary, from an educational point of view, there needs to be a dynamic relationship between the critical and the creative dimensions of media literacy. Young people need to learn to make media, but they also need to reflect systematically on what they have done, and to analyse it in the light of a broader awareness of how the media work.

TC: The influence of media messages has established itself as a central concern in both popular and scholarly criticism of child media, especially as regards violence and gender stereotypes. While child media producers have always taken pains to present themselves as socially responsible (for example through the adoption of industry codes), many media content producers now seem to show greater concern in their portrayal of gender and race: for example, much of Disney animation's current output qualifies as somewhat "woke," suggesting a growing recognition of the studio's social responsibilities in presenting images that defy stereotypes. The My Little Pony: Friendship is Magic reboot was likewise devised by its creator as a platform for a positive take on "girliness." How do you interpret the US child media's more overtly political ambitions?

DB: Yes, indeed, there's quite a long and interesting history to all this! As a Cultural Studies researcher, I have always been very suspicious of the notion of "influence"whether we are talking about positive or negative influences. The idea that media have straightforward "effects" that work in one direction is obviously a massive oversimplification. That's the case whether we're talking about violence and gender stereotyping, or about "pro-social" influences. There's an assumption that we can make changes at the level of the text which will then have guaranteed consequences for the reader.

21 When it comes to "pro-social" influences, there are further problems. The idea that we can embed morally or politically correct lessons into children's content has a very long history, of course; but we know from audience research that these messages are interpreted in many different ways, which don't always correspond with the producers' intentions. There's often a contradiction here between the call to eliminate stereotypes and create "accurate" representations, on the one hand; and the call to provide "positive images" that will somehow automatically empower particular sections of the audience, on the other. Here too, we know from audience research that "positive images" don't necessarily have positive effects-and indeed that images may well be positive in some ways and not in others, or for some people and not others. And I'm not sure that we could ever think without "stereotypes" of some form. These are all highly problematic, contested terms. 

media critics: it has become stock-in-trade of the media industries. As you imply, there is a danger that companies are merely paying lip-service to what they imagine is politically correct: "positive images" in areas such as gender and ethnicity often seem to reflect a kind of superficial tokenism. But it would be unduly cynical to regard this as solely a matter of "brand management": there has been a genuine shift in the media's awareness of these issues-albeit one that has been slow in coming, and is still very partial. In some areas, we seem to move forwards only to fall back at a later stage: for example, at least in Britain, some of the progress that was made during the 1970 s and 1980s in terms of multicultural representation in children's books seems to have gone into reverse in recent years. easy to point to some quite offensive gender and racial stereotyping in Disney's early films (Song of the South is the classic example), and Uncle Walt himself had some very dubious sympathies. But at least since the 1990s, the company has sought to globalise its output: many of the key films from that period (Pocahontas and Mulan, for example) attempt to address issues of gender and race, albeit in ways that are sometimes awkward and ambivalent. Uncle Walt always insisted that his films were not just for children, but for family audiences (which apart from anything else, would prove significantly more lucrative). They had to appeal to adults as well-and in addition to addressing adults' nostalgia for "childhood innocence," they also had to address adults' concerns about representation. I was part of an international research project in the 1990s that addressed this cross-generational appeal of Disney (it was published in a book called Dazzled by Disney); and researchers in many countries found a striking ambivalence in adults' responses.

My Little Pony is another interesting case. The original cartoon series of the 1980s were discussed in some detail in one of the most influential books on children's media, Ellen Seiter's Sold Separately. Seiter argues against the critics who complained about the "saccharine" storylines and limited stereotypes of these series. She argues that the programmes themselves were more complex, but also that they created a separate space for "girliness" that might even be empowering for girls. It's interesting to see the same argument recurring around the "reboot" you mention-not least because those who produced the new version would have grown up enjoying the original series. What might have been an implicit benefit of the original series has now perhaps become a self-conscious, deliberate strategy-and of course, it's also a marketing strategy, that could well overcome the objections of middle-class parents.

There's room for debate about all this, of course; but my key point is that this is by no means a new phenomenon. One of the key aims of children's media has always been to "do children good"-not least because children's access to media is often partly mediated and controlled by adults, and because these media have to be "sold" to parents as well as children. In some instances, of course, this is little more than window-dressing: the producers of violent cartoons, for example, will typically defend themselves by pointing to the pro-social messages such cartoons apparently promote, and indeed the moralistic homilies with which they often conclude. I don't think it's a surprise now to find that children's media are increasingly purveying politically correct or "woke" messages, for parents as well as children. 

intensified individualism, not just in our use of media content, but in social life much more broadly. Yet at the same time, there also appears to be an intensification of connectedness. There is so much more media content out there; and as a result, audiences have become increasingly fragmented. There might seem to be much less of a "common culture," for example when we compare with an age in which there were only one or two television channels. Yet at the same time, we have many more opportunities to share and discuss media content; and of course, as we do this, we are also making claims about who we are, or who we want to be-we are "performing identity" in multiple ways. Turkle put it well in entitling her book Alone Together-although I wouldn't share the technological determinism she seems to adopt. Individualisation and connectedness appear to go together, in a kind of spiral. The more alone we feel, the more intensely we wish to connect; and the stronger our connection, the more solitude comes to feel like loneliness. We can't switch off. And of course this feeds into the business model of social media: the more we share and like and connect, the more data the companies have about us (and about our media and consumer preferences), and the more money they make. 
31 This applies to most of us, but it has a particular relevance to youth culture. Youth culture is based on a fundamental dynamic. It is about asserting individuality, but also about affiliating with the group. Through displaying our media and consumer tastes, we demonstrate our distinctiveness, and our position in terms of social hierarchies. Young people will often claim that their affiliation with a particular style is somehow a natural expression of who they really are; and they will differentiate themselves from the "fakers" and the "wannabees," who are simply following fashion. Social media didn't create this dynamic, although I believe they intensify it. Social media allow companies to insert their products and services right into the heart of youth culture, in the everyday relationships of the peer group; and this allows those relationships to be monetised, to become a source of financial profit.

This is obviously less intense when it comes to younger children, although children are arguably "getting older younger," as some of the marketing gurus tell us. The success of the YouTube influencers we were discussing earlier is perhaps a symptom of this: they are effectively "consumer advisers," offering guidance on how to perform identity in a world that displays a bewildering range of possibilities. Becoming a "tween" means you have to negotiate your way through a complicated web of such advice-on how to be cool and stylish, and even sexy; how to be boyish or girlish; and how to "act your age."

So to answer your question directly: I would say that social media might intensify some of these processes of identity performance, and it certainly commercialises them in new ways. There is more at stake, perhaps, because more of this is being conducted in public, and less in private. We can share our performances more widely, in more visual forms, although equally it is harder for us to retain control over what then happens to this material. Even so, I suspect the basic processes themselves, and the motivations that drive them, are very similar to what they were with older media.

TC: I would like to turn to the industry's creation of audiences, whose marketing efforts essentially operate as self-fulfilling prophecies, helping create groups that they allegedly merely address and now identifying ever-more niche markets, such as tweens. In contrast with such laser-focused targets, some products enjoy unexpected success with audiences well outside the range of their intended demographic, with the consumption by adults of products ostensibly meant for children (as with "Bronies," male adult fans of the My Little Pony: Friendship is Magic franchise). What do you make of the interplay between intended and unintended audiences, and what does it suggest about marketers' success and failures in creating audiences for child media products?

DB: You're certainly right about this circular process of constructing audiences. It's something that has a history in children's media-"teenagers" (in the 1950s) and "tweens" (in the 1990s) are obvious examples-but there is an even longer history in other areas of marketing to children. Dan Cook's work on the children's clothing industry shows how the children's market was progressively segmented through the early decades of the last century. Of course, the creation of new categories (like "toddlers") is partly a reflection of consumers' needs: toddlers are not just a particular size, but also a particular shape, and they need clothes that will fit them! But it is of 
course something that also reflects the needs of the market: segmentation makes for greater profitability, at least if you do it right.

Likewise, with children's media, this is a multidimensional process. The "tween" is effectively invented as a distinct category, and market researchers are brought in to identify and to theorise its specific developmental "needs." Tweens are then targeted with tween-specific media that claim to meet those needs, for example by showing aspects of tween life, or addressing tweens' specific aspirations and anxieties. The more complex question is to do with how far those in this tween group actually come to identify themselves as tweens-that is, as a distinctive group, possessing needs and characteristics that the media and marketers have apparently identified. I think we need to know more about the meanings and indeed pleasures of this for audiences, and how and why they might resist it.

Niche markets make some kind of economic sense-especially if they can be built on a global scale-but there is also a risk of cutting the cake into ever-finer slices. There's also the question of what might get lost in this process. For example, if we look at the products that are targeted in their direction, it seems that tweens are generally assumed to be girls. Where are the boy tweens, or does such an idea make any sense at all?

The other issue, of course, is that children can be quite promiscuous in terms of how they respond to age-based segmentation. The US magazine Seventeen has a substantial readership that is much younger than its name suggests; children have often been particularly keen on TV shows that feature teenagers or twenty-somethings (Friends would be the obvious example); and I've interviewed teenagers who have an ambivalent nostalgic-ironic fascination with pre-school programmes. Successful franchises like Pokemon will often include a range of products that appear to target different ages (soft toys, TV cartoons, complex games); but this also allows children to cut across these seemingly well-defined age categories-to aspire to be older than they are, or regress to be younger, without stepping outside the confines of the brand.

When we come on to adults' engagement with children's media and consumer products, this process takes on a further complexity. As I've suggested, children's media are often implicitly targeted at parents as well. They often have to pass through a process of parental gatekeeping (not least because it's mostly parents who are paying); and in some instances (as with Disney) they are sometimes addressing both audiences simultaneously, albeit in different ways. These media are often intended to be consumed cross-generationally; and so there have to be things there for adults as well as children. Again, this isn't new: you could look at The Flintstones, Sesame Street, Harry Potter, Spongebob Squarepants, and so on. In some ways, it's the texts that seem to allow fewer points of entry for adults-some preschool TV, perhaps, or some of the boyoriented animation series, or indeed Pokemon-that are really in need of a closer look.

The phenomenon of adult fandom, which you're referring to here, is to some extent a different matter. In some cases, there may be an element of nostalgia here-a sense of mourning for the childhoods we have lost. We can see some of this in the contemporary adult fans of "cult" children's series of the 1970s and 1980s, or of certain children's books (in Britain, the popular children's author Enid Blyton is one such focus for this). But there is often a kind of irony at stake here, as well: we know a whole lot more than we did as children, and there is a kind of literal-minded childishness about these things that we can no longer take seriously, even if we wanted to. 

(for example in Sherilyn Connelly's book Ponyville Confidential), there seems to be a struggle for ownership or legitimacy going on here. On the one hand, you have longerterm fans, who are mostly female: they are partly motivated by nostalgia for the original series, and partly by a genuine (rather than ironic) identification with the series producers, and the themes and characters. And then you have the Bronies, who are almost exclusively male, and who do not seem to have been fans of the original series. For them, there may be a kind of extraneous identification going on: the appeal is about engaging in "fannish" activities for their own sake, albeit in a somewhat ironic and even "camp" way (although that is quite difficult to read), as much as it is about this particular series. to regard this kind of fandom as typical of media audiences in general; and to that extent, I regret the prominence it enjoys in Media and Cultural Studies. There's too much celebration in the world of "fan studies," and too little critical analysis. In cases like the Bronies, I wouldn't presume to psychoanalyse what's going on; but I do think there's a risk that such adult fannish phenomena are appropriating children's culture for their own purposes-and in the process, they might be taking it away, or even spoiling it, for children themselves.

So, to answer your question directly: I don't think it's so easy to draw a distinction between intended and unintended audiences, and it's not necessarily a good idea to map onto that a binary distinction between adults and children. Producers might imagine they can "laser-focus" their targets, as you put it; but this may be a necessary fantasy for them, because they know that real audiences are much less predictable and much harder to control.

TC: One trait commonly held as central to US society is that of consumerism. Child media has proved critical in this area, as it may be understood at least in part as an effort to create an audience not just for media products but for child-centric ads promoting specific toys, foods, or other consumer products. In the US likely more than anywhere else, children's exposure to ads and commercial messages has been articulated in terms of their rights as consumers-often by the same politicians who decry children's exposure to violent or sexual media content. How do you explain such contradictory assessments of children's agency and literacy, which alternatively depict child audiences either as active and critical, or as passive and undiscriminating?

DB: I recognise what you're saying: in a commercially-driven media system, the creation of audiences is always the creation of markets. But I have a few problems with the notion of "consumerism." Talking about "consumerism" seems to imply that there is a kind of psychological malaise here, even a kind of individual weakness. In line with other arguments about media effects, this charge is often directed at other people. The problem here is to do with women, who are apparently compulsive "shopaholics"; or working-class people, who obstinately persist in making ill-advised, tasteless consumer choices; and of course children, who are apparently so easily manipulated by advertisers and marketers. On the other hand, my own (adult, male, middle-class) 
consumption is entirely justified: my purchasing behaviour is rational and not excessive, and it merely demonstrates my own innate good taste.

The idea of "consumerism" stands in a long tradition of psychologising social problems. Once we have defined the issue in this way, then we can enumerate all the various characteristics of consumerism, and correlate them with other problematic personality traits, not least exposure to "bad media" of various kinds. There is a kind of moral judgement only a little way beneath the surface of this, whereby we blame these other people for their misguided, undisciplined behaviour-or in the case of children, implicitly blame their parents. Thus are research traditions created. Yet psychologising the issue inevitably displaces attention from the broader social context, and the deeper structural causes of what concerns us. Personally, I think we should be talking about capitalism, not about consumerism.

Some years ago, I led an enquiry for the UK government on this issue-some of which later ended up in my book The Material Child. There were some very clear instances of this kind of displacement of attention going on. One example of this was the debate about advertising and child obesity. When you look hard at the evidence, it's clear that the effects of advertising in this area have been vastly overstated. Obesity is a multifactorial problem; but it's very evident that poor people are much more likely to be obese than affluent people. It's about inequality, and how that affects the choices people have available to them. Blaming advertising for child obesity distracts attention from these other issues, in a way that's very convenient for politicians: it allows them to be seen to be doing something, while actually avoiding the bigger causes. (And of course we can see the same kind of distraction or displacement going on in other debates about media effects, most obviously in the case of violence.)

What I tried to do with my enquiry was to broaden the terms of this debate. The government clearly wanted me to look at psychological effects-indeed, my report was entitled (not by me) "The Impact of the Commercial World on Children's Wellbeing." I argued that "the commercial world" is by no means solely about advertising, or even marketing more broadly; and that “wellbeing” wasn't just a psychological matter. So I had sections in my report about the commercialisation and privatisation of children's welfare and play facilities, and of the education system. These are certainly aspects of the "commercial world" which have significant implications for "wellbeing"-although they were clearly not what the government wanted the report to talk about! I refused to give them what they wanted, and so they buried the report.

Let me be clear. My argument is not that media have no "effects"-although (as I said before) I don't think that "effects" or "influence" are very useful ways of talking about this. Rather, I am arguing that we need to take a broader view: blaming advertising (or media more generally) effectively lets politicians off the hook-it allows them to pass the blame for social problems on to evil marketers, and indeed to individuals themselves.

50 This doesn't mean that I am "defending" marketers-and I don't think these polarised, dichotomous ways of framing the issue are very helpful either. I have been pretty scathing about marketers' claims about children's consumer autonomy, and the kind of vacuous psychobabble they are based upon. Marketers do bear some ethical responsibility for how they target children. There are genuine reasons for concern, especially about the newer, less "visible" forms of digital marketing that are aimed at kids; and these practices should be more tightly regulated. But it's a dangerous fantasy 
to imagine that you will solve much broader social problems-obesity, violence, sexism, whatever-simply by controlling children's access to media.

51 As your question implies, there are some significant contradictions-as well as some awkward coincidences-in this debate. Marketers have been very good at mobilising ideas about children's agency and children's rights, in ways that echo the claims of some child advocates. Equally, left-wing critics' claims about "media influence" often come close to those of the moralists on the political right. If you look at the debate about "sexualisation," for example, you can see some quite surprising alliances: some feminist critics seem to line up with marketers, emphasising girls' agency as consumers, while others line up with the religious Right, with their arguments about keeping girls safe and pure.

Yet in some ways, this reinforces my point: these are political issues, and we need to debate and address them as such. Framing the issues in such dichotomous terms, and appealing to generalised assertions about children's essential qualities-their innocence and vulnerability, or alternatively their innate wisdom and "savvy"-doesn't really help us to address the more fundamental problems that are at stake.

TC: Thank you so much, David Buckingham, for agreeing to this interview and sharing these insights.

\section{BIBLIOGRAPHY}

Buckingham, David. The Material Child: Growing Up in Consumer Culture. Cambridge, UK: Polity, 2011.

Connelly, Sherilyn. Ponyville Confidential: The History and Culture of My Little Pony, 1981-2016. Jefferson: McFarland, 2017.

Cook, Dan T. The Commodification of Childhood: The Children's Clothing Industry and the Rise of the Child Consumer. Durham: Duke University Press, 2004.

Seiter, Ellen. Sold Separately: Parents and Children in Consumer Culture. New Brunswick: Rutgers University Press, 1993.

Turkle, Sherry. Alone Together: Why We Expect More from Technology and Less from Each Other. New York: Basic Books, 2011.

Wasko, Janet, Mark R. Phillips, and Eileen R. Meehan. Dazzled by Disney? The Global Disney Audiences Project. Leicester: Leicester University Press, 2001. 


\section{ABSTRACTS}

David Buckingham is internationally known for his work on children, young people and media, and media education. $\mathrm{He}$ is an Emeritus Professor of Cultural Studies at Loughborough University, and a Visiting Professor at Kings College, University of London, UK. This written interview was conducted by Thibaut Clément in October 2020. David Buckingham's blog, along with numerous essays and articles, can be found at: www.davidbuckingham.net.

Entretien avec David Buckingham, dont les travaux sur les enfants, la jeunesse et les médias, ainsi que sur l'éducation aux médias sont internationalement connus. Professeur émérite d'études culturelles à Loughborough University, David Buckingham est chercheur invité à Kings College, University of London, au Royaume-Uni. Cet entretien avec Thibaut Clément s'est déroulé en octobre 2020. Le blog de David Buckingham, qui contient de nombreux essais et articles, peut être consulté à l'adresse www.davidbuckingham.net.

INDEX

Keywords: children, youth, media, media education, television, United States

Mots-clés: enfants, jeunesse, médias, éducation aux médias, télévision, États-Unis

\section{AUTHORS}

\section{THIBAUT CLÉMENT}

Sorbonne Université

DAVID BUCKINGHAM

Loughborough University 